Article

\title{
Geomorphologic Analysis of Small River Basin within the Framework of Fractal Tree
}

\author{
Meiyan Feng ${ }^{1}$, Kwansue Jung ${ }^{2}$ and Joo-Cheol Kim ${ }^{1, *}$ \\ 1 International Water Resources Research Institute, Chungnam National University, 99 Daehak-ro, \\ Yuseong-gu, Daejeon 34134, Korea; pungmiyom@gmail.com \\ 2 Department of Civil Engineering, Chungnam National University, 99 Daehak-ro, Yuseong-gu, \\ Daejeon 34134, Korea; ksjung@cnu.ac.kr \\ * Correspondence: kjoocheol@hanmail.net; Tel.: +82-42-821-8958
}

Received: 27 June 2020; Accepted: 1 September 2020; Published: 4 September 2020

check for updates

\begin{abstract}
This paper presents the modified framework of geomorphologic analysis based on the concept of fractal tree. Especially, it is intended to provide hydrologic practitioners with the information on the fractal property of small river basins. To this end, the complete drainage path network is applied to a growth process of a fractal tree for the basin of interest by connecting a channel network to overland drainage pathways. The growth process of a fractal tree would occur only within the limited region possessing channel flow properties in a natural river basin. The exponent of the intra basin type of Hack's law could show a variable trend in small river basins mainly due to anisotropic property of the catchment planform. The bifurcation process of a drainage path network might be more sensitive to the growth step of the fractal tree than the meandering process of drainage path segment. The fractal dimension from the sinuosity of a channel segment is relatively stable compared to the one from the bifurcation process of the network, so that the geomorphologic features of a small river basin can be characterized by the anisotropic property of catchment planform as well as the bifurcation property of drainage path network with the growth of the fractal tree.
\end{abstract}

Keywords: fractal tree; small river basin; fractal dimension; Hack's law

\section{Introduction}

During recent decades, fractal geometry [1] as well as self-organized criticality [2] have been used as important tools to analyze complex natural phenomena that cannot be fully explained by Euclidian geometry and classical physical laws. It is interesting for both of the theories to consider empirical geomorphologic properties of the river basin such as Horton's law and Hack's law to be the prototype of complexity from nature. It can be regarded to be evidence that a river basin is a representative complex natural system which consists of dynamic interactions among numerous components with many degrees of freedom [3]. In effect, a river basin has been defined as a kind of complex transformation system with rainfall turning into runoff through a lot of interactions between overland and channel networks, so that it would evolve constantly with a wide spatiotemporal scale in order to effectively drain rainfall. Therefore, it might be impossible to analyze geomorphologic features of river basin by only using a simple type of governing equations such as Newton's law [2].

Advances in geographic information technology with DEM (digital elevation model) allow us to devise the geomorphologic descriptors of river basin that cannot be achieved on paper maps [4], and promote a variety of approaches to geomorphologic structure of river basin. Especially, since the concept of threshold area to form a channel on a DEM [5], various methodologies have been proposed to simulate output for salient properties of a channel network [6-9], in which the degree of space-filling by the channel network could be measured quantitatively in terms of a spatial dimension. 
For instance, Tarboton et al. [10] estimate the fractal dimension of a channel network extracted from DEM by using the Richardson's method and box counting scheme, where they suggest that a channel network of a river basin is a kind of fractal object having two distinct fractal dimensions, one from the sinuosity of the channel segment and the other from a bifurcation process of the network. La Barbera and Rosso [11] and Rosso et al. [12] propose the relation of fractal dimension for channel network combined with Horton ratios. A series of studies are, subsequently, conducted on the relation between fractal dimension and the law of drainage composition [13,14]. It is noteworthy that Agnese et al. [15] suggest fractal dimension of a channel network as a function of its magnitude within the framework of a link ordering scheme [16]. It can be thought of as the notable efforts devoted by hydrologists and geomorphologists for the sake of establishing a general theory of channel network structure with the combination of empirical geomorphologic laws and fractal geometry.

Recently, Kim and Jung [17] try to estimate the fractal dimension of a natural river basin by using the concept of fractal tree. Fractal tree is a fractal object continuously developing according to self-similarity in that a linear segment bifurcates to cover a planar space [18]. The authors assume the growth processes of fractal tree and channel network approaches are identical to each other in order to approach a bifurcation structure of channel network. However, they only focus on the bifurcation process of a network structure without considering sinuosity of channel segment in detail. Thereby, the main purpose of this study is to modify their methodology and propose the more advanced theoretical framework for fractal dimensions of channel network to overcome their limitation. Furthermore, this study tries to apply the modified framework to geomorphologic analysis on a river basin in Korea. Due to the fact that most hydrologic practices in Korea are concerned with small- and middle-scale river basins, a case study is conducted on a small river basin. This is intended to provide hydrologic practitioners with the information on fractal property about small river basins beyond the asymptotic property of fractal nature frequently pointed out by many previous studies [19-21] and the basic tool to bridge a theoretical gap related to basin scale on the basis of the fractal tree concept.

\section{Theoretical Background}

\subsection{Horton's Law}

Strahler's stream ordering scheme has been well known for assigning the topology of channel networks [22]. The following points summarize its main ideas.

- Channels that originate at a source are defined to be the first-order streams.

- When two streams of order $\omega$ join a stream of order $\omega+1$ is generated.

- When two streams of different orders join, the channel segment immediately downstream has the higher order of the two combining streams.

Once the topology of a channel network is assigned following Strahler's stream ordering scheme, Horton's law or the law of drainage composition can be defined [22]

$$
\begin{aligned}
R_{B} & =\frac{N_{\omega-1}}{N_{\omega}} \\
R_{L} & =\frac{L_{\omega}^{s}}{L_{\omega-1}^{s}} \\
R_{A} & =\frac{A_{\omega}}{N_{\omega-1}}
\end{aligned}
$$

where $R_{B}, R_{L}$ and $R_{A}, L_{\omega}^{s}$ and $A_{\omega}$ being the number, average length, and average drainage area of the $\omega$ th order stream, respectively. 


\subsection{Hack's Law}

On the assumption of a rectangle enclosing a single river basin, of which the longitudinal length is $L_{\|}$with the traverse length being $L_{\perp}\left(L_{\|}>L_{\perp}\right)$, drainage area $A$ can be related to those

$$
A \propto L_{\|} L_{\perp}
$$

According to anisotropic property of catchment planform, scaling laws for $L_{\perp}$ and $A$ can be expressed in terms of $L_{\|}$

$$
\begin{aligned}
& L_{\perp} \propto L_{\|}^{H} \\
& A \propto L_{\|}^{H+1}
\end{aligned}
$$

where $H$ is the Hurst exponent in the range of 0 to 1 [19]. Sinuosity of channel segment or main channel length $L$ can be also expressed in the form of scaling law

$$
L \propto L_{\|}^{d_{L}}
$$

where $d_{L}$ is the fractal dimension of a single channel segment with the typical value being about 1.1 to $1.2[10]$.

By substituting Equation (6) into Equation (7), Hack's law can be given, one of the most well-known empirical relations for natural river basins [23]

$$
L \propto A^{h} ; h=\frac{d_{L}}{H+1}
$$

where $h$ is the Hack's exponent. It is well known that the value of $h$ often tends to be greater than 0.5 [24]. Rosso et al. [12] propose a relation for $d_{L}$ in terms of Horton's law by combing Equations (2) and (3) with Equation (8)

$$
d_{L}=(H+1) \frac{\ln R_{L}}{\ln R_{A}}
$$

It should be noted that $H$ in the right hand side of Equation (9) has the value of unity in the original formulation [12]. This might be due to regarding the catchment planform as the isotropic one following Mandelbrot [1], so that Equation (9) could be considered to be a more general type of relation for $d_{L}$ than the one discussed elsewhere [12].

\subsection{Fractal Tree}

The morphometric properties of channel network could be explained by the growth process of a fractal tree (Figure 1.13, p. 22, [18]). It starts with a single trunk of unit length. If $N$ branches of length $\lambda,(0<\lambda<1)$ grow out of the trunk and the same procedure is repeated at the finer scales, the number and length, $N_{k}$ and $r_{k}$, respectively, of branches at the $k$ th growth step can be computed

$$
\begin{aligned}
& N_{k} \propto N^{k} \\
& r_{k} \propto \lambda^{k}
\end{aligned}
$$

The total number of branches with the length being equal or greater than $r_{k}, N\left[r_{k}\right]$, can be also calculated by using the geometric series

$$
N\left[r_{k}\right]=\sum_{i=0}^{k} N^{i}=\frac{N^{k+1}-1}{N-1}
$$


By substituting Equations (10) and (11) into Equation (12) and then replacing $\ln N / \ln \lambda$ by $-d_{N}$, Equation (12) can be transformed into power law distribution [17]

$$
N\left[r_{k}\right] \propto r_{k}{ }^{-d_{N}}
$$

where $d_{N}$ is the fractal dimension of fractal tree stemming from the bifurcation process. If a channel network embedded in a river basin is regarded as a kind of fractal tree, Equations (1) and (2) conceptually coincide with Equations (10) and (11); the number of branches and their changing rate in length by growth step of fractal tree correspond to the bifurcation and length ratio of Horton's law, respectively. Therefore, the fractal dimension of channel network can be written in terms of Horton's law

$$
d_{N}=\frac{\ln R_{B}}{\ln R_{L}}
$$

$\lambda$ in Equation (11) refers to a reduction rate of branches in fractal tree while $R_{L}$ stands for an elongation rate of streams in channel network. It means that they have opposite signs to each other. Being completely identical to the fractal dimension of the channel network proposed by La Barbera and Rosso [11] based on Horton's law, Equation (14) indicates scaling behavior of a channel network, in that linear channel segments organize a kind of network structure in order to fully drain a planar basin by a bifurcation process with the space-filling of the channel network.

\section{Methodology}

\subsection{Study Site}

Our study site is the Seolma creek basin located in the middle west of the Korean peninsula. It is one of the small tributary basins, with the drainage area of about $9.68 \mathrm{~km}^{2}$, into the Imjin river system which is flowing through the border between South and North Korea. The Seolma creek basin is geologically composed of the Gyeonggi gneiss of the Precambrian period. It belongs to a typical mountainous region with the proportion of forest being about $77 \%$, in which the mean elevation and slope are EL. $171.66 \mathrm{~m}$ and $15.79^{\circ}$, respectively. It can be characterized by a continental climate with the annual average temperature and precipitation being $10.2^{\circ} \mathrm{C}$ and $1391.2 \mathrm{~mm}$, respectively. It is noted that the Seolma creek basin has been rarely developed during the last century due to its geopolitical location with South and North Korea and can be, thus, regarded to be in a mostly natural condition.

Figure 1 shows the drainage map of the basin of interest in this study, in which its outlet (Jeil) is selected from the inside of the Seolma creek basin. The channel network (Blue Line) depicted in Figure 1 comes from digital terrain map by National Geographic Information Institute (NGII) Korea at the scale of 1:25,000. From the preliminary inspection of topology for the channel network in Figure 1, it can be seen that the channel segment immediately downstream from the Jeil has the Strahler's stream order of three. Therefore, the upstream part of the Jeil enclosed by the basin boundary is drained through a single 2nd order stream network which can be regarded as the fully matured fractal tree at the 1st growth step. This is the main reason for us choosing it as the study site. It is also noticed that the study area of interest is identical with the one from the previous research related to the fractal dimension of channel network conducted in another study [17]. 


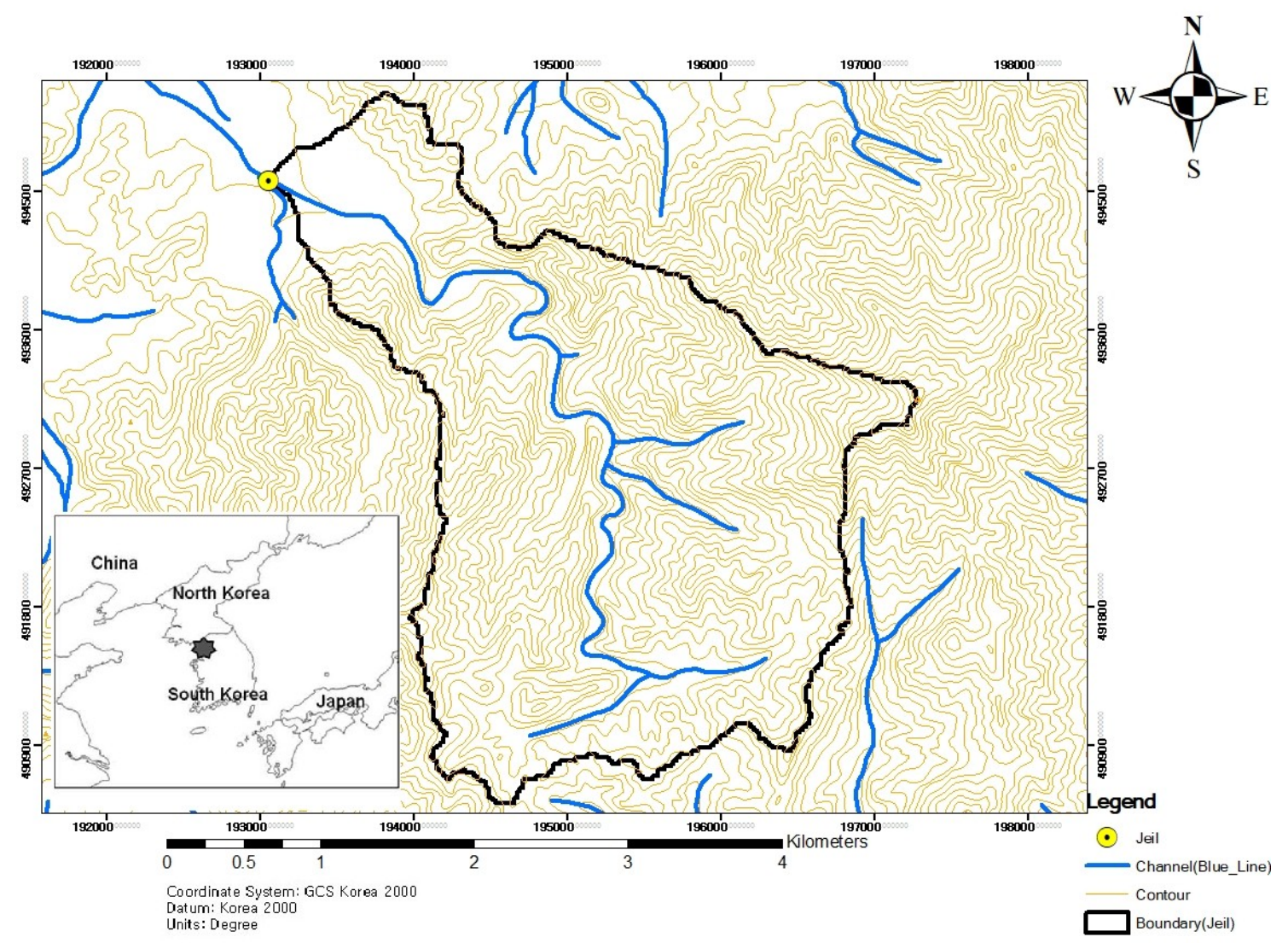

Figure 1. Drainage Map of the Basin of Interest (The Jeil).

\subsection{Geomorphologic Analysis}

In this study, a DEM for the basin of interest is generated in the resolution of $20 \times 20 \mathrm{~m}$ by using digital terrain map of NGII Korea at the scale of 1:25,000. TauDEM [9], operated on ArcMap, is applied to the manipulation of the resulting DEM and the construction of a drainage path network by an eight-flow direction method. As a preprocess for DEM, the stream-burning process [25] is utilized in order to extract the drainage path network which resembles much closer to the field surveyed channel network (Blue line in Figure 1). Following the previous work [17], the complete drainage path network is applied to a growth process of fractal tree in this study. The complete drainage path network, so called, could be constructed by identifying all possible drainage paths from every point to the outlet on DEM, which fulfills ultimately the whole drainage area by connecting channel network to overland drainage paths. The topology of resulting drainage path network is assigned by Strahler's stream ordering scheme, in that each stream order can be interpreted as the successive growth step of the fractal tree in an inverse order. Initially, there is only one stream of order $\Omega$ in a basin of order $\Omega$. It can be considered to be the trunk or initiator of the fractal tree. The streams of order $\Omega-1$ are created at the 1st growth step of a fractal tree and then the streams of order $\Omega-2$ occur at the 2nd growth step. The same procedure is repeated as the growth step increases until the branches of the fractal tree arrive at the basin boundary. Similarly to the pruning process of network tree [26], such topologic features of the 1st-order stream as $N_{1}, L_{1}^{s}$, and $A_{1}$ are successively evaluated for every fractal tree created at each growth step. This is intended to avoid confusing the Strahler's stream with the link (channel segment between adjacent two nodes). Especially, the straight-line length is also measured between both ends of every 1st-order stream at each growth step for the sake of a scaling relation of the Strahler's stream length described in the next section. 


\subsection{Scaling Relations}

This study assumes a scaling relation for $L_{\omega}^{s}$ in a similar form to Equation (7) [27]

$$
L_{\omega}^{s} \propto\left(L_{\omega \|}^{s}\right)^{d_{L}}
$$

where $L_{\omega \|}^{s}$ is the average straight line length between the both ends of the $\omega$ th order stream. It can be noticed that it plays the same role as $L_{\|}$in Equation (7). If $r_{k}$ in Equation (13) is replaced by, in turn, $L_{\omega}^{s}$ and $L_{\omega \|}^{s}$ according to Equation (15), Equation (13) can be converted into

$$
\begin{gathered}
N\left[L_{\omega}^{s}\right] \propto\left(L_{\omega}^{s}\right)^{-d_{N}} \\
N\left[L_{\omega \|}^{s}\right] \propto\left(L_{\omega \|}^{s}\right)^{-D} ; D=d_{N} d_{L}
\end{gathered}
$$

Equation (16), previously proposed by Kim and Jung [17], represents the relation for $d_{N}$ on the basis of the fractal tree concept. It can be easily seen that there might be no way to estimate $d_{L}$ within the framework of Equation (16) since there is no explicit consideration for $d_{L}$ within it. On the other hand, in the context of Strahler's stream ordering scheme, it is clear that $N\left[L_{\omega}^{s}\right]$ and $N\left[L_{\omega \|}^{s}\right]$ of a single channel network have the same value each other. Therefore, $D$ in Equation (17) corresponds to the fractal dimension of the channel network as a whole because the Strahler's stream is itself a fractal with dimension $d_{L}$ under the assumption of Equation (15). Additionally, thereby, it is possible to estimate $d_{L}$ as well as $d_{N}$ by conjunctive use of Equations (16) and (17). This is the essence of the modified framework for the fractal dimension of a channel network suggested in this study. It is noticed that Equations (16) and (17) are parallel with the relations for fractal dimension based on stream length exceedance probability proposed by Tarboton et al. [10].

This study also assumes that Equation (8) is still valid with Horton's law in a single river basin [20]. Therefore, a scaling relation is postulated in this study instead of Equation (8)

$$
L_{\omega} \propto\left(A_{\omega}^{h}\right) ; L_{\omega}=\sum_{i=1}^{\omega} L_{i}^{s}
$$

where $L_{\omega}$ can be interpreted as the length of main channel for the $\omega$ th order basin.

All of the scaling relations presented in this section are based on the assumption of Equation (15). Therefore, this study tries to analyze geomorphologic features of the basin of interest by using those relations as well as to verify the validity of Equation (15) itself through a case study.

\section{Results and Discussion}

\subsection{Construction of Fractal Tree}

Figure 2 is the fractal tree constructed for the basin of interest in this study, where the order in the legend is established by applying Strahler's stream ordering scheme to the fractal tree fully grown up. It can be seen that the stream order of the fractal tree trunk is six and the basin is thus completely fulfilled after five steps of growth. Table 1 lists the topologic features of the fractal tree, in which the stream order $\omega$ is counted in an inverse order of the growth step $k(\omega=\Omega-k)$. It is noted that the branches out of the 4th and 5th growth steps have similar values of $L_{\omega}^{s}$ and $L_{\omega \|}^{s}$, two measures of Strahler's stream length, respectively. It means that the branches from the final step could have different growth properties than the ones from the previous steps, in that they would tend to consist of the drainage pathways on an overland flow region. In other words, the growth process of the fractal tree terminates at the fourth growth step in the basin of interest, so that the bifurcation structure of the branches stemming from the final step would be different than the ones from the previous steps. Therefore, it could be expected that the growth process of a fractal tree in a natural river basin would occur only within the limited region possessing the channel flow property. 


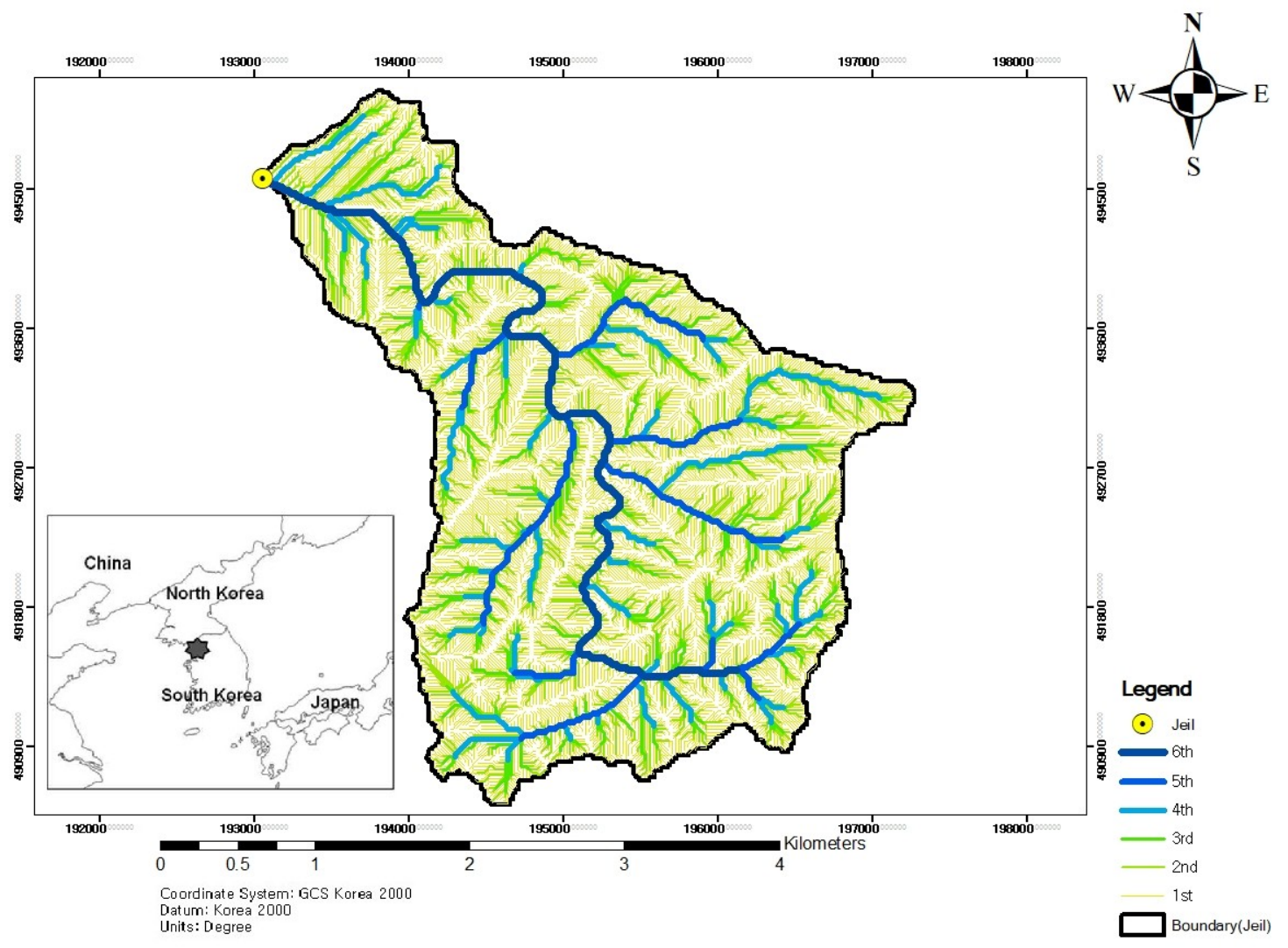

Figure 2. Fractal Tree of the Basin of Interest (The Jeil).

Table 1. Topologic Features of Fractal Tree in the Basin of Interest (The Jeil).

\begin{tabular}{cccccc}
\hline $\boldsymbol{k}$ & $\boldsymbol{\omega}$ & $\boldsymbol{N}_{\boldsymbol{\omega}}$ & $\boldsymbol{L}_{\boldsymbol{\omega}}^{s}(\boldsymbol{m})$ & $\boldsymbol{L}_{\boldsymbol{\omega} \|}^{\boldsymbol{s}}(\boldsymbol{m})$ & $\boldsymbol{A}_{\boldsymbol{\omega}}\left(\boldsymbol{m}^{2}\right)$ \\
\hline 5 & 1 & 5711 & 72 & 69 & 1192 \\
4 & 2 & 1310 & 78 & 74 & 4876 \\
3 & 3 & 271 & 117 & 110 & 17,957 \\
2 & 4 & 61 & 279 & 254 & 85,344 \\
1 & 5 & 11 & 779 & 675 & 544,000 \\
0 & 6 & 1 & 7018 & 4413 & $9,678,800$ \\
\hline
\end{tabular}

\subsection{Scaling of Strahler's Stream Length}

Figure 3 and Table 2 show a scaling relation of $L_{\omega}^{s}$ in terms of $L_{\omega \|}^{s}$ following the assumption of Equation (15). The order in the legend of Figure 3 corresponds to $k$ (the growth step of fractal tree or the network itself created at the $k$ th growth step) and the vertical scales are adjusted by the factor of $10^{k-1}$ vertically to avoid overlapping of the curves. Therefore, the exponents of regression in Table 2 show the variation of $d_{L}$ with the growth of the fractal tree. The coefficient of determination for the regression of the first growth step is unity because there are only two plotting points in that case. 


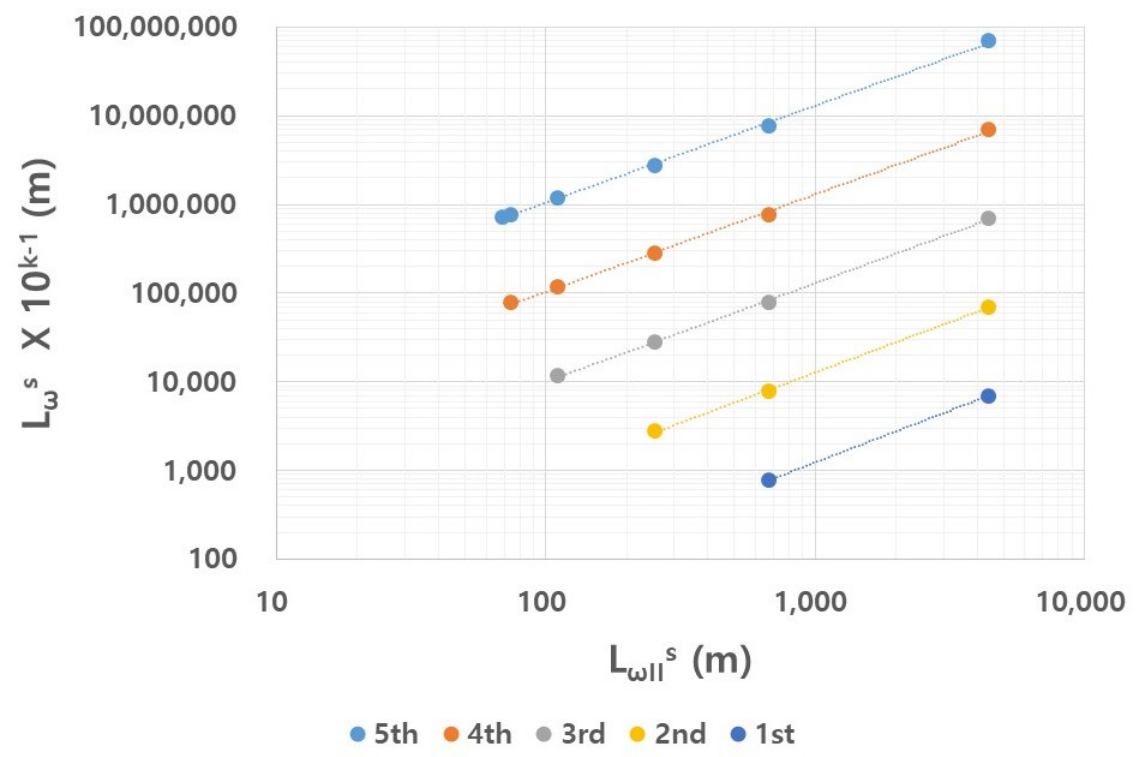

Figure 3. Scaling Relation of Stream Length for the Basin of Interest (The Jeil).

Table 2. Regression of Stream Length for the Basin of Interest (The Jeil).

\begin{tabular}{cccc}
\hline $\boldsymbol{k}$ & Regression & $\boldsymbol{R}^{2}$ & $\boldsymbol{d}_{\boldsymbol{L}}$ \\
\hline 5 & $L_{\omega}^{s}=0.6754\left(L_{\omega \|}^{s}\right)^{1.0951}$ & 0.9991 & 1.0951 \\
4 & $L_{\omega}^{s}=0.6554\left(L_{\omega \|}^{s}\right)^{1.0993}$ & 0.9990 & 1.0993 \\
3 & $L_{\omega}^{s}=0.6022\left(L_{\omega \|}^{s}\right)^{1.111}$ & 0.9990 & 1.1110 \\
2 & $L_{\omega}^{s}=0.2019\left(L_{\omega \|}^{s}\right)^{1.1354}$ & 0.9993 & 1.1354 \\
1 & $L_{\omega}^{s}=0.3792\left(L_{\omega \|}^{s}\right)^{1.1708}$ & 1.0000 & 1.1708 \\
\hline
\end{tabular}

It can be seen that there is a trend of decreasing $d_{L}$ as the fractal tree grows up. Therefore, by pruning the branches of each stream order, in turn, from the fractal tree in Figure 2, one can see that the longer and more winding branches appear. From the view point of basin hydrology, it might be due to the variable contribution of overland flow (which is known to be in the form of sheet flow with a parallel drainage pathway) at each growth step into the channel flow. That means the sinuosity of the channel segment would become more profound with the increase in the stream order accompanied with the decrease in contribution from overland flow. It is noticed that $d_{L}$ for the basin of interest is in the range of about 1.1 to 1.2 , the same as proposed by [10], and the difference between the successive growth steps is from $10^{-2}$ to $10^{-3}$ orders of magnitude. In addition, the different growth properties of the final branches out of the fractal tree, already addressed in the previous section, can be found in the first two plotting points of the uppermost curve in Figure 3.

\subsection{Scaling of Catchment Planform}

Figure 4 and Table 3 describe a scaling relation of $A_{\omega}$ by Equation (6) with the assumption of Equation (15), and in the same manner of Figure 3. Behavior can be seen that is similar to the scale break in the first two to three plotting points of the first two upper curves in Figure 4. It could be due to the discriminate growth pattern of final branches out of the fractal tree as mentioned before. In addition, the planforms of the first and second stream order basins (created at the fifth and fourth growth steps, respectively), implicitly embedded in Figure 2, could be formed in different ways compared to the ones of the higher stream order. Within the framework of Strahler's stream ordering scheme, every basin of the stream order $\omega$ greater than two usually has the one confluence at which the two drainage paths 
of the stream order $\omega-1$ merge, which are fed by the lateral tributaries of the lower stream order less than $\omega-1$. Additionally, it also has the one drainage path of the stream order $\omega$ with the lateral tributaries of the lower stream orders less than $\omega$. In addition, thereby, the planform of the $\omega$ th stream order basin enlarges and widens according to Equations (5) and (6) as the stream order increases. However, the first stream order basin has a linear shape of planform following a single drainage path from the basin boundary to the outlet without any upstream tributary and the well-defined width itself. In the second stream order basin there is the one confluence at which the two drainage paths of the stream order one merge resulting in the linear and narrow upstream part. Additionally, it gets enlarged and widened only by the single second order drainage path fed by the lateral drainage paths of the stream order one. It can be thus expected that the scale break in Figure 4 could be caused by the different growth pattern of the planform of the first and second stream order basins. That means, only the regressions for the first to third growth steps in Table 3 could adequately reflect the anisotropic property of catchment planform in the basin of interest according to Equation (6). Therefore, it could be thought of that the first and second stream order basins belong to overland flow region, in which the former follows the pure overland flow regime and the latter shows some degree of channel flow pattern. It is noted that there is a trend of increasing $H$ within the value of 0.5 to 0.7 following the first to third growth steps of the fractal tree. It is also noticed the difference between the successive growth steps is larger by one order of magnitude than $d_{L}$.

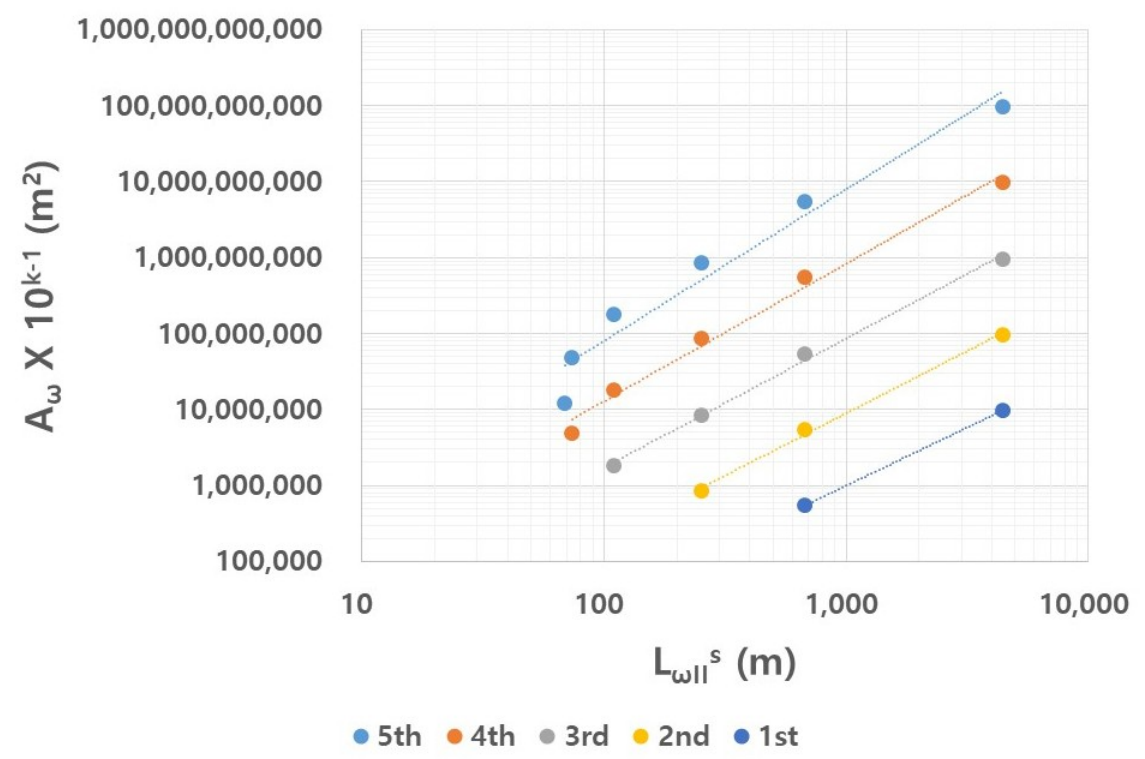

Figure 4. Scaling Relation of Drainage Area for the Basin of Interest (The Jeil).

Table 3. Regression of Drainage Area for the Basin of Interest (The Jeil).

\begin{tabular}{cccc}
\hline $\boldsymbol{k}$ & Regression & $\boldsymbol{R}^{2}$ & $\boldsymbol{H}$ \\
\hline 5 & $A_{\omega}^{s}=0.8325\left(L_{\omega \|}^{s}\right)^{1.9924}$ & 0.9557 & 0.9924 \\
4 & $A_{\omega}^{s}=3.0643\left(L_{\omega \|}^{s}\right)^{1.8111}$ & 0.9892 & 0.8111 \\
3 & $A_{\omega}^{s}=6.8268\left(L_{\omega \|}^{s}\right)^{1.7004}$ & 0.9969 & 0.7004 \\
2 & $A_{\omega}^{s}=10.686\left(L_{\omega \|}^{s}\right)^{1.6405}$ & 0.9969 & 0.6405 \\
1 & $A_{\omega}^{s}=24.932\left(L_{\omega \|}^{s}\right)^{1.5335}$ & 1.0000 & 0.5335 \\
\hline
\end{tabular}




\subsection{Hack's Law in a Single River Basin}

Figure 5 shows an intra basin type of Hack's law [20], so called, by using Equation (18). With the consideration of the variable geometric property of catchment planform according to the growth of the fractal tree, three drainage path networks of the first to third growth step are selected from Figure 2 and reordered by Strahler's stream ordering scheme. Then, the main channel length $L_{\omega}$ is calculated by Equation (18). Table 4 lists the variation of $h$ with the growth of fractal tree, in which $h_{o b s}$ comes from the curves in Figure 5 whereas $h_{\text {cal }}$ is computed by Equation (8).

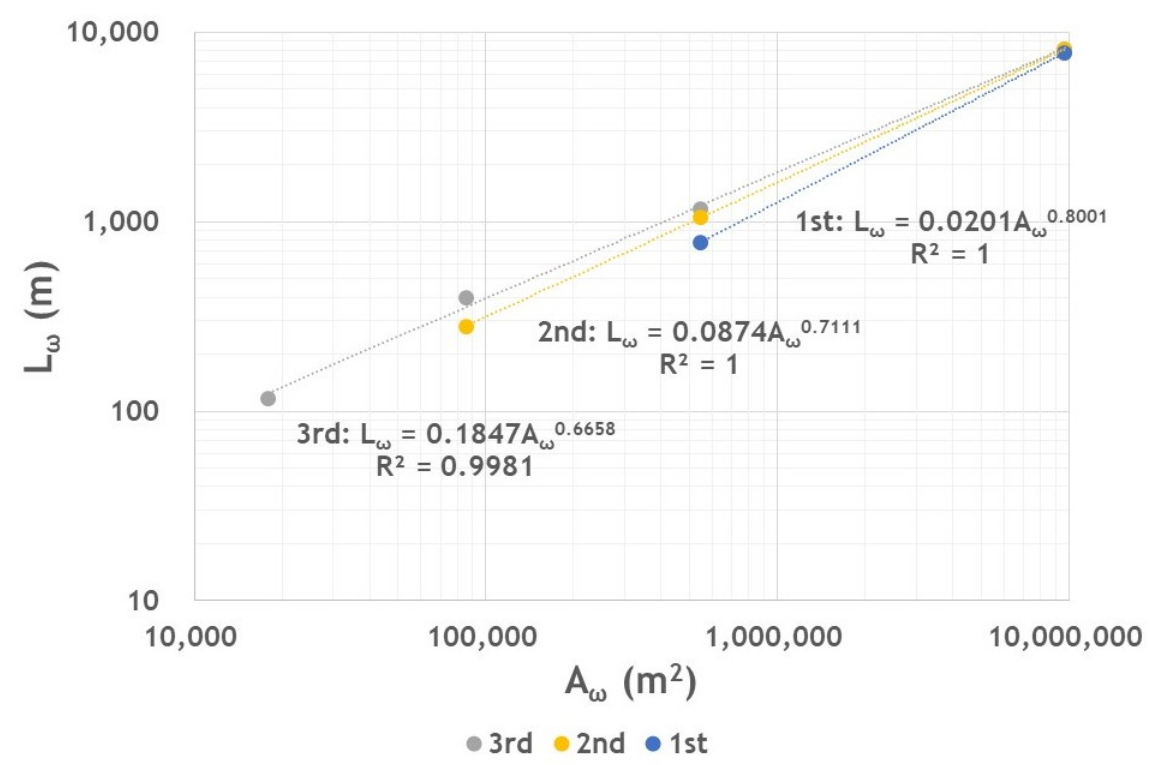

Figure 5. Intra Basin Type of Hack's Law for the Basin of Interest (The Jeil).

Table 4. Regression of Hack's Law for the Basin of Interest (The Jeil).

\begin{tabular}{ccccc}
\hline $\boldsymbol{k}$ & Regression & $\boldsymbol{R}^{2}$ & $\boldsymbol{h}_{\text {obs }}$ & $\boldsymbol{h}_{\text {cal }}$ \\
\hline 3 & $L_{\omega}=0.1847 A_{\omega}^{0.6658}$ & 0.9981 & 0.6658 & 0.6534 \\
2 & $L_{\omega}=0.0874 A_{\omega}^{0.7111}$ & 1.0000 & 0.7111 & 0.6916 \\
1 & $L_{\omega}=0.0201 A_{\omega}^{0.8001}$ & 1.0000 & 0.8001 & 0.7635 \\
\hline
\end{tabular}

It can be seen that, within the first to third growth steps of the fractal tree, $h_{c a l}$ and $h_{o b s}$ have the similar values at each growth step and show the similar variation trend; furthermore, the variation of $h$ is mainly attributed from $H$. This might be a different result compared with the ones with the stable $h$ from the previous studies $[19,20]$ which mainly focus on the middle- and large-scale basins with the drainage area greater than $20 \mathrm{~km}^{2}$. Dodds and Rothman [21] present the variation trend of $h$ in the intra basin type of Hack's law, where they point out that an intermediate scaling regime exists between the pure overland flow and well-developed channel flow regimes, and the intermediate scaling regime cannot provide the stable $h$. Due to the fact that the aggregation of significant drainage areas can give rise to the well-developed channel flow, the intermediate scaling regime is likely to be dominant in a small river basin. As mentioned before, the basin of interest in this study falls into the typical type of small river basin in Korea with the area of much less than $20 \mathrm{~km}^{2}$. Therefore, it could be judged that the variation trend of $h$ within the first to third growth steps in Table 4 might be the reasonable one and depends on anisotropic property of catchment planform in the basin of interest in this study. 


\subsection{Estimation of Fractal Dimension by Fractal Tree}

Figure 6 shows the relations of Equations (16) and (17) for the basin of interest in this study, where the plotting points show the linear trend in the tail part and the departure trend nearby the origin. More specifically, it can be seen that the first two plotting points of each curve represent the behavior of overland flow region as seen before. Therefore, similarly to the previous section, the bifurcation structure is sought for the three drainage path networks of the first to third growth steps. Table 5 lists the estimates of fractal dimensions, where $D$ and $d_{N}$ come from the regression by Equations (16) and (17) and, furthermore, $d_{L}$ is indirectly computed by Equation (17). The straight lines in Figure 6 demonstrate the regressions for $D$ and $d_{N}$ in the case of the third growth step. It is noticed that the both estimates of $d_{L}$ in Tables 2 and 5 have the similar values at each growth step even though they have the different sources. Therefore, Equations (16) and (17) could be thought of as the useful framework to estimate the two distinct fractal dimensions of a natural river basin on the basis of the fractal tree concept.

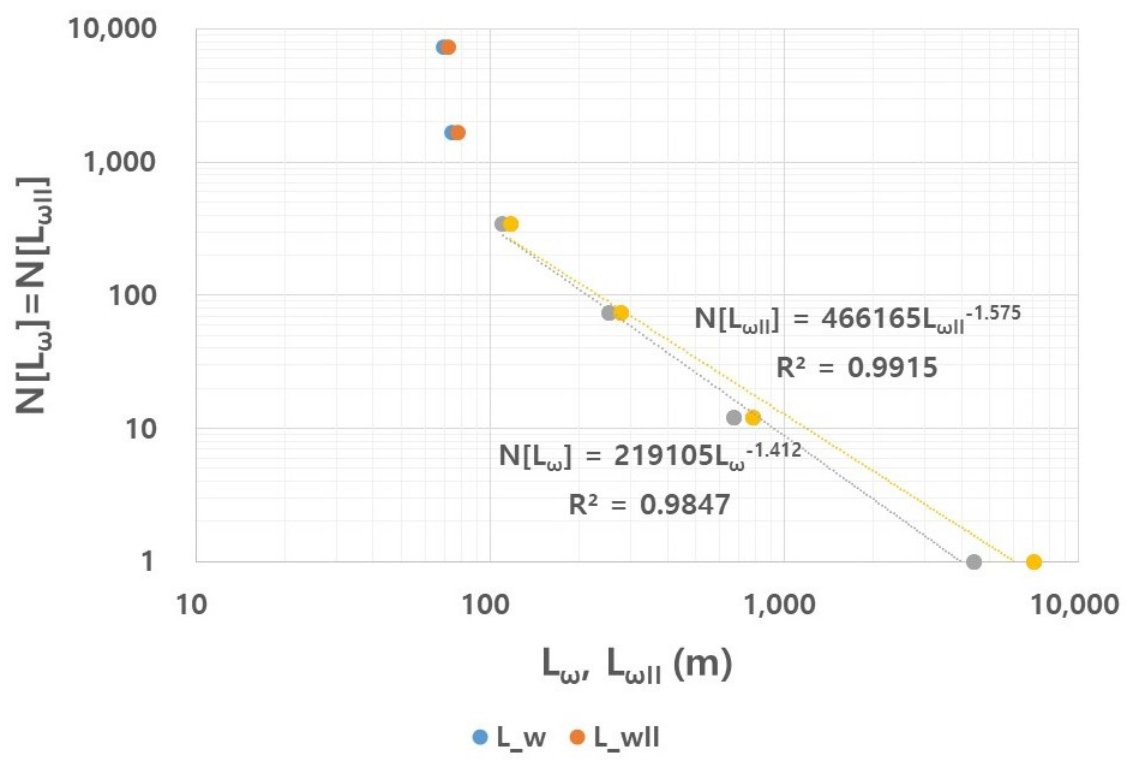

Figure 6. Fractal Dimensions at the 3rd Growth Step for the Basin of Interest (The Jeil).

Table 5. Regression of Stream Length for the Basin of Interest (The Jeil).

\begin{tabular}{cccc}
\hline$k$ & $D$ & $d_{N}$ & $d_{L}$ \\
\hline 3 & 1.5750 & 1.4120 & 1.1150 \\
2 & 1.4790 & 1.2980 & 1.1390 \\
1 & 1.3240 & 1.1310 & 1.1706 \\
\hline
\end{tabular}

Notably, the variation of $d_{N}$ is larger by one order of magnitude than $d_{L}$ with the growth of the fractal tree. It indicates that the bifurcation process of the drainage path network might be more sensitive to the growth step of the fractal tree than the meandering process of the drainage path segment. Thereby, although the three drainage path networks in Table 5 are successively superposed from the first growth step to the third growth step, the different bifurcation structures, reflected in $d_{N}$, appear at each growth step of the fractal tree. This is a parallel result with the variation of $h$ in the intermediate scaling regime presented in the previous section (Table 4). So, it can be inferred that the scale invariance of a channel network, frequently suggested by previous research [19-21], would be asymptotically valid as the scale of a river basin increases with the well-developed channel flow being dominant. On the other hand, in the case of a small river basin, it can be expected that its main 
part tends to follow the intermediate scaling regime with $h$ being variable and then its effect can be reflected in the variation of $d_{N}$. Because $d_{L}$ is relatively stable to $d_{N}$, the geomorphologic features of a small river basin can be characterized by the anisotropic property of catchment planform as well as the bifurcation property of the drainage path network with the growth of the fractal tree.

Figure 7 shows the expanded fractal tree into the whole Seolma creek basin, in order to validate the assumption of Equation (15) as well as the modified framework with Equations (16) and (17). The Imjin, located downstream of the Jeil, is the main outlet of the Seolma creek basin, which corresponds to the inlet into the Imjin river as mentioned before. Furthermore, the Jeonjeokbi in Korean (JJB), located upstream of the Jeil, is the outlet of the experimental basin operated by KICT (Korea Institute of Civil Engineering and Building Technology). It can be seen that the highest stream order is seven for the Imjin subbasin $\left(A=17.60 \mathrm{~km}^{2}\right)$, one order higher than the Jeil subbasin (the basin of interest in this study), whereas the JJB $\left(A=8.44 \mathrm{~km}^{2}\right)$ is the same as the Jeil. Therefore, the former can be regarded as the fully matured fractal tree of the order of seven and the latter is the not fully matured fractal tree of the order six.

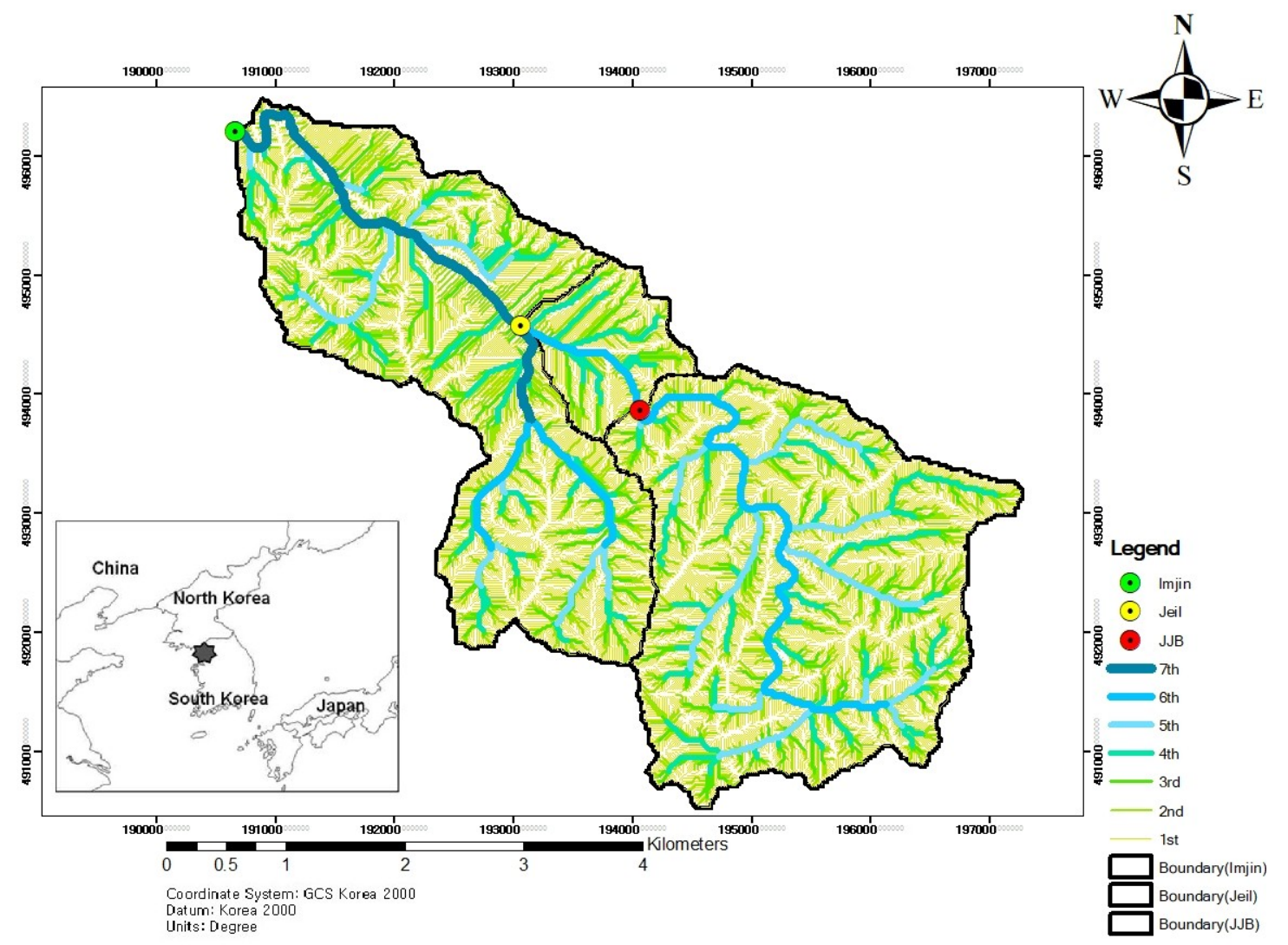

Figure 7. Subdivision of Fractal Tree for the Seolma Creek Basin (The Imjin, the Jeil, and the JJB).

Following the last two previous sections, the first and second stream order basins embedded in Figure 7 can be considered to belong to overland flow region. In addition, thereby, Table 6 lists the fractal dimensions of the resulting three drainage path networks for the three outlets (JJB, Jeil, Imjin) in Figure 7. $d_{\text {Lobs }}$ comes from the regression by Equation (15), while $d_{\text {Lcal }}$ is indirectly computed with $D$ and $d_{N}$ from the regression by Equations (16) and (17). Similar to Table 5, both estimates of $d_{L}$ in Table 6 have the similar values, so that the modified framework suggested in this study could be confirmed as the useful tool for the estimation of two distinct fractal dimensions on the basis of the fractal tree concept. 
Table 6. Fractal Dimension of the Seolma Creek Basin.

\begin{tabular}{ccccccc}
\hline Outlet & $\boldsymbol{A}\left(\mathbf{m}^{2}\right)$ & $\boldsymbol{k}$ & $\boldsymbol{d}_{\text {Lobs }}$ & $\boldsymbol{D}$ & $\boldsymbol{d}_{\boldsymbol{N}}$ & $\boldsymbol{d}_{\text {Lcal }}$ \\
\hline JJB & $8,444,800$ & 3 & 1.1422 & 1.6520 & 1.4400 & 1.1472 \\
Jeil & $9,678,800$ & 3 & 1.1110 & 1.5750 & 1.4120 & 1.1150 \\
Imjin & $17,598,400$ & 4 & 1.0844 & 1.8050 & 1.6590 & 1.0880 \\
\hline
\end{tabular}

\subsection{Further Discussion}

\subsubsection{Interpretation of Drainage Path Network}

Figure 8 shows the blue line in Figure 2 which is superposed on the drainage path network of the third growth step of the fractal tree. Usually, such a channel network as the blue line in Figure 2 is built on the basis of the field survey. So, it can be reasonable to regard those as the extent of perennial stream network of the basin of interest. Even at a glance, one can see easily the difference between the two networks in Figure 7. Based on the evidence presented in the previous sections, the drainage path network of the third growth step can be considered as a kind of collection of the overland flow parts possessing the channel flow property characterized by the anisotropic feature of catchment planform as well as the bifurcation structure. In other words, there may exist many drainage pathways on the overland flow region which cannot form channels in the dry season whereas, in the rainy season, they could form the ephemeral stream network around the perennial one and play the similar role as channel network. Furthermore, the contribution cannot be ignored of the ephemeral stream network into the drainage process in small river basin without the well-developed channels. Therefore, the drainage path network depicted in Figure 8 could be expected to provide more useful information than the blue line network in Figure 8 for the hydrologic practices on the design flood in a small river basin.
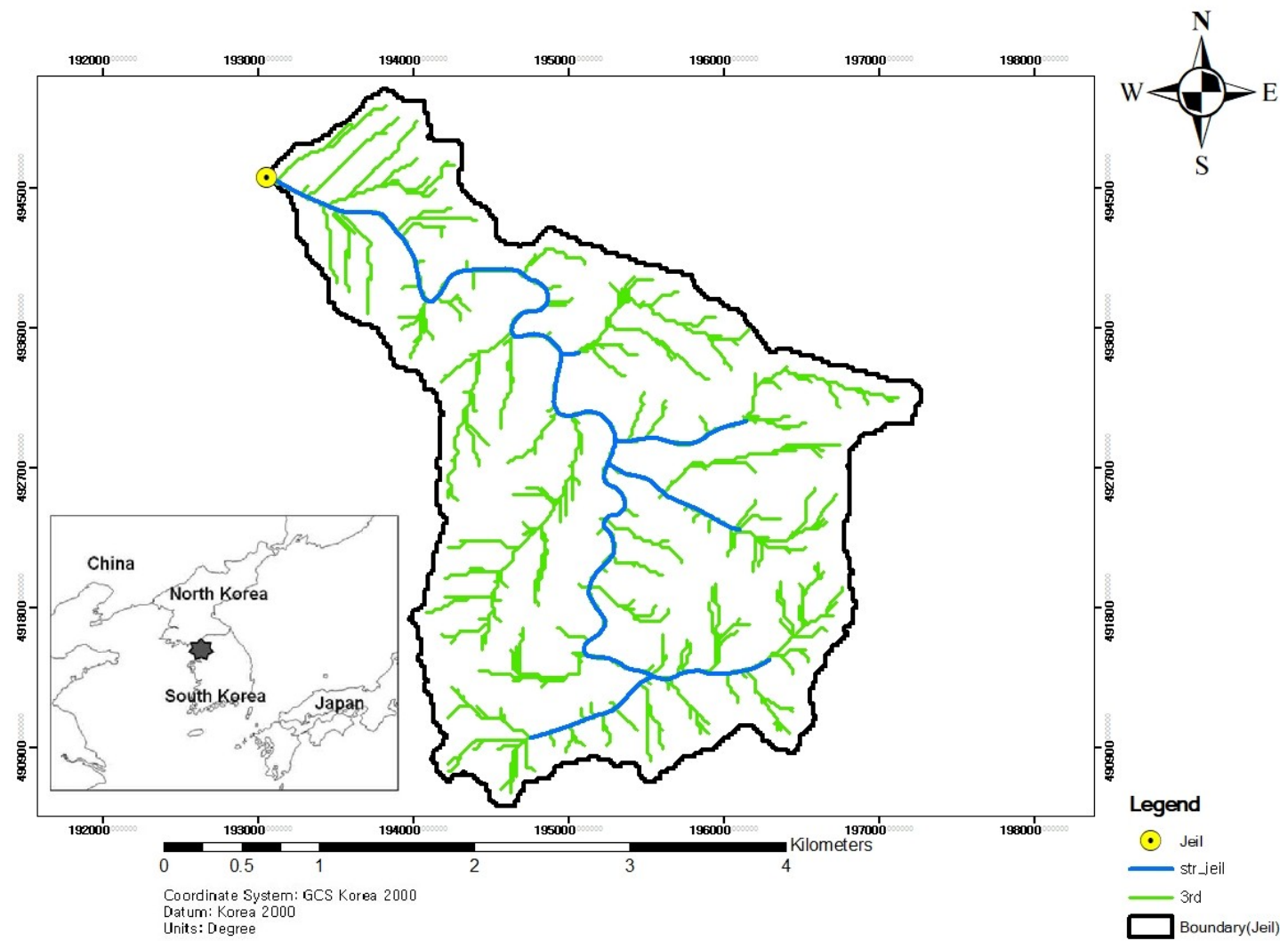

Figure 8. Drainage Path Network of the Basin of Interest (The Jeil). 
Based on the drainage path network similar to Figure 8, Kim and Jung [17] suggest the relation of $d_{N}$ within the framework of Equation (16). However, they cannot provide an explicit relation for $d_{L}$ as there is no appropriate tool in their framework to clearly assess it. Therefore, the conjunctive use of Equations (16) and (17), which is suggested in this study, could provide a more advanced theoretical framework for the fractal dimensions of a channel network to overcome their limitations.

\subsubsection{Potential Usage of Fractal Tree Concept}

As mentioned before, the previous studies for fractal dimensions of channel networks [19-21] mainly focus on the middle- and large-scale basins. However, many hydrologic practices, at least now in Korea, tend to be concerned with the small scale basins. This is likely to be due to the continuous expansion of urban areas with the national economic development. As the cities expand, small territories around urban areas adjacent to the mountainous region might be required to accommodate an increased population. So, it is necessary to establish the framework of geomorphologic analysis for small-scale basins beyond the asymptotic property of fractal nature for the middle- and large-scale basins. We believe this kind of trend could be common all over the world in the near future and the methodology suggested in this study might be useful to bridge a theoretical gap related to basin scale on the basis of the fractal tree concept.

Recently, the scaling and topology of urban drainage networks are investigated by using scaling relations widely used for channel networks [28]. In this context, the degree of space-filling by urban drainage networks might be an indicator of drainage effectiveness for urban landscapes and the framework suggested in this study could provide a quantitative measure in terms of fractal dimension.

\section{Conclusions}

The noteworthy results from this study are as follows:

(1) The growth process of the fractal tree in a natural river basin would occur only within the limited region possessing the channel flow property. Sinuosity of the channel segment would become more profound with the increase in the stream order accompanied with the decrease in contribution from overland flow.

(2) In the framework of a fractal tree, the first and second stream order basins would belong to the overland flow region, in which the former follows the pure overland flow regime and the latter shows some degree of channel flow pattern.

(3) The exponent of the intra basin type of Hack's law could show the variable trend in a small river basin depending on the anisotropic property of the catchment planform. The bifurcation process of a drainage path network might be more sensitive to the growth step of a fractal tree than the meandering process of drainage path segment.

(4) Because the fractal dimension of the sinuosity of a channel segment is relatively stable compared to the one from a bifurcation process of a network, the geomorphologic features of a small river basin can be characterized by the anisotropic property of the catchment planform as well as the bifurcation property of the drainage path network with the growth of the fractal tree.

(5) There may exist many drainage pathways on the overland flow region which cannot form channels in the dry season whereas, in the rainy season, they could form the ephemeral stream network around the perennial one and play the same role as the channel network.

Author Contributions: Conceptualization, J.-C.K.; methodology, J.-C.K.; software, M.F. and J.-C.K.; validation, K.J. and J.-C.K.; formal analysis, J.-C.K.; investigation, M.F. and J.-C.K.; resources, K.J. and J.-C.K.; data curation, J.-C.K.; writing_-original draft preparation, M.F. and J.-C.K.; writing-review and editing, K.J. and J.-C.K.; visualization, M.F. and J.-C.K.; supervision, J.-C.K.; project administration, J.-C.K.; funding acquisition, J.-C.K. All authors have read and agreed to the published version of the manuscript. 
Funding: This research was supported by the National Research Foundation of Korea (NRF-2019R1I1A1A01063063) and Korea Environment Industry \& Technology Institute (KEITI) through Advanced Water Management Research Program, funded by Korea Ministry of Environment (MOE) (79610).

Conflicts of Interest: The authors declare no conflict of interest.

\section{References}

1. Mandelbrot, B.B. The Fractal Geometry of Nature; W.H. Freeman: New York, NY, USA, 1982.

2. Bak, P. How Nature Works; Copernicus: New York, NY, USA; Springer: New York, NY, USA, 1996.

3. Rodriguez-Iturbe, I.; Ijjasz-VasquezR, E.J.; Bras, R.L.; Tarboton, D.G. Power law distributions of discharge, mass, and energy in river basins. Water Resour. Res. 1992, 28, 1089-1093. [CrossRef]

4. Moussa, R. On morphometric properties of basins, scale effects and hydrological response. Hydrol. Process. 2003, 17, 33-58. [CrossRef]

5. O'Callaghan, J.F.; Mark, D.M. The extraction of drainage networks from digital elevation data. Comput. Vision Graph. Image Process. 1984, 28, 324-344.

6. Tarboton, D.G.; Bras, R.L.; Rodriguez-Iturbe, I. A physical basis for drainage density. Geomophology 1992, 5, 59-75. [CrossRef]

7. Montgomery, D.R.; Foufoula-Georgiou, E. Channel network source representation using digital elevation models. Water Resour. Res. 1993, 29, 3925-3934. [CrossRef]

8. Ijjasz-Vasquez, E.J.; Bras, R.L. Scaling regimes of local slope versus contributing area in digital elevation models. Geomorphology 1995, 12, 299-311. [CrossRef]

9. Tarboton, D.G. Terrain Analysis Using Digital Elevation Models in Hydrology. In Proceedings of the 23rd ESRI International Users Conference, San Diego, CA, USA, 7-11 July 2003.

10. Tarboton, D.G.; Bras, R.L.; Rodriguez-Iturbe, I. The Fractal nature of river networks. Water Resour. Res. 1988, 24, 1317-1322. [CrossRef]

11. La Barbera, P.; Rosso, R. On the Fractal dimension of stream networks. Water Resour. Res. 1989, 25, 735-741. [CrossRef]

12. Rosso, R.; Bacchi, B.; La Barbera, P. Fractal relation of mainstream length to catchment area in river networks. Water Resour. Res. 1991, 27, 381-387. [CrossRef]

13. Beer, T.; Borgas, M. Horton's law and the Fractal nature of streams. Water Resour. Res. 1993, 29, $1475-1487$. [CrossRef]

14. Puente, C.E.; Castillo, P.A. On the Fractal structure of networks and dividers within a watershed. J. Hydrol. 1996, 187, 173-181. [CrossRef]

15. Agnese, C.; D'Asaro, F.; Grosso, G.; Rosso, R. Scaling properties of topologically random channel network. J. Hydrol. 1996, 187, 183-193. [CrossRef]

16. Shreve, R.L. Statistical law of stream numbers. J. Geol. 1966, 74, 17-37. [CrossRef]

17. Kim, J.C.; Jung, K. Fractal Tree Analysis of Drainage Patterns. Water Resour. Manag. 2015, 29, $1217-1230$. [CrossRef]

18. Hergarten, S. Self-Organized Criticality in Earth System; Springer: New York, NY, USA, 2002.

19. Maritan, A.; Rinaldo, A.; Rigon, A.; Giacometti, A.; Rodriguez-Iturbe, I. Scaling laws for river networks. Phys. Rev. E 1996, 53, 1510-1515. [CrossRef]

20. Rigon, R.; Rodriguez-Iturbe, I.; Maritan, A.; Giacometti, A.; Tarboton, D.G.; Rinaldo, A. On Hack's law. Water Resour. Res. 1996, 32, 3367-3374. [CrossRef]

21. Dodds, P.S.; Rothman, D.H. Scaling, Universality, and Geomorphology. Ann. Rev. Earth Planet. Sci. 2000, 28, 571-610. [CrossRef]

22. Smart, J.S. Channel networks. Adv. Hydrosc. 1972, 8, 346-350.

23. Hack, J.T. Studies of Longitudinal Profiles in Virginia and Maryland; US. Geological Survey Professional Paper: Washington, DC, USA, 1957; Volume 294-B, pp. 45-97.

24. Gray, D.M. Interrelationships of watershed characteristics. J. Geophys. Res. 1961, 66, 1215-1223. [CrossRef]

25. Saunders, W.K.; Maidment, D.R. A GIS Assessment of Nonpoint Source Pollution in the San Antonio-Nueces Coastal Basin; Center for Research in Water Resources, University of Texas at Austin: Austin, TX, USA, 1996.

26. Dodds, P.S.; Rothman, D.H. Unified View of Scaling Laws for River Networks. Phys. Rev. E 2000, $59,4865$. [CrossRef] 
27. Kim, J.C.; Jung, K. Estimation of Fractal Dimension for Seolma Creek Experimental Basin on the Basis of Fractal Tree Concept. J. Korea Water Resour. Assoc. 2020. stage of publication. (under review). (In Korean)

28. Yang, S.; Paik, K.; McGrath, G.; Urich, C.; Kruger, E.; Kumar, P.; Rao, P.S.C. Comparing Topology of Engineered and Natural Drainage Networks. Water Resour. Res. 2017, 53, 8966-8979. [CrossRef]

(C) 2020 by the authors. Licensee MDPI, Basel, Switzerland. This article is an open access article distributed under the terms and conditions of the Creative Commons Attribution (CC BY) license (http://creativecommons.org/licenses/by/4.0/). 